\title{
An unhappy 10th birthday: Doctors of the World's London clinic
}

\author{
Richard Hurley
}

The BMJ

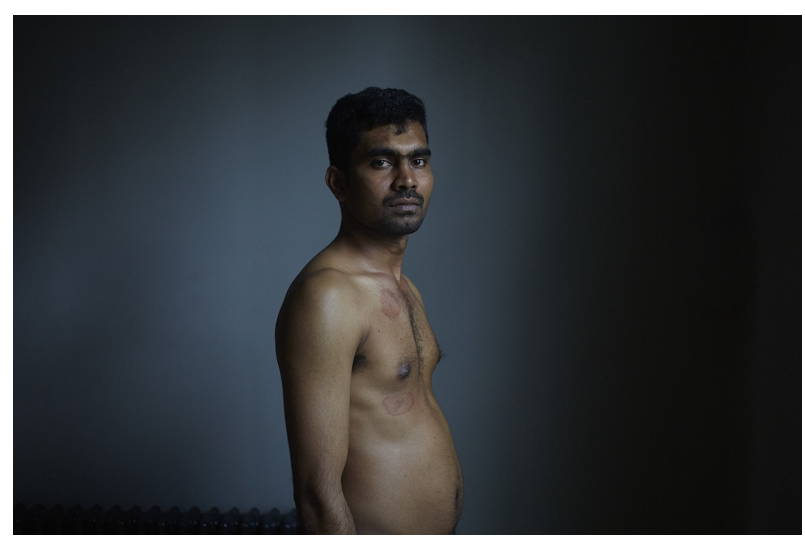

[lmage: Jenny Lewis/Doctors of the World]

For a decade the humanitarian charity Doctors of the World has been running a clinic in east London to help vulnerable people who are otherwise unable to access healthcare. The patients include refugees and undocumented migrants, some of whom have been trafficked or tortured.

For an exhibition to mark the occasion several photographers have contributed portraits of the clinic's users and volunteer staff. The Sri Lankan man pictured escaped to London after being tortured and forced to leave his country. No general practice would register him despite his needing urgent medical help.

"I have a lot of pain on the body and I am not sleeping well, I have really bad dreams," he says in the exhibition catalogue. "I think a lot, reliving things."

In theory everyone in the UK is entitled to free primary healthcare. In practice many people, including pregnant women and seriously ill people, are refused GP registration because they don't have identification or proof of address. Others are too frightened to seek care because they fear an expense or being reported to the authorities.

Thelma Thomas, a GP and one of the clinic's volunteers, says, "I've been struck by the extent of trauma people have experienced, but also their resilience. Working at Doctors of the World breaks down myths and barriers-you're talking to people, not to migrants."

Since the clinic first opened in Bethnal Green in 2006 demand has tripled, and the clinic now has 1600 users a year.

In this year's Queen's speech the government proposed legislation to extend healthcare charges for foreigners, and the Department of Health for England has consulted on implementation in primary and emergency care.

Leigh Daynes, executive director of Doctors of the World, said, "Ten years on our Bethnal Green clinic is needed now more than ever as successive governments make it harder for vulnerable, destitute migrants to get the healthcare they are entitled to.

"Ensuring access to primary care is not only the right thing to do; it's the smart thing to do in protecting the public purse and assuring public health. Yet ignorance, discrimination, and exclusion continue to drive our patients underground. The people who come to our clinic are often isolated, desperate, and frightened."

Nick Harvey, the charity's communications manager, said, "It's certainly not a celebration-we should not have to be here at all."

The media gave prominence to the recent anniversary of the death of the 3 year old Syrian refugee boy Aylan Kurdi. Photos of his lifeless body washed up on a Turkish beach led to international outrage last September. But as "refugee fatigue" sets in, much suffering goes unreported. Huge numbers of people have been displaced by violence in countries such as Syria, Afghanistan, and Somalia.

The United Nations Refugee Agency recently reported that worldwide 65.3 million people were displaced at the end of 2015, up from 59.5 million the year before-roughly the population of the UK. The vast majority (86\%) of them are in developing countries. Half of them are children.

The exhibition, Undocumented: Healthcare for the Hidden, runs 7-10 September 2016 at the Four Corners Gallery, London E2 0QN. Doctors of the World is keen to find venues to host the show after that. See www.printsforrefugees.com to buy prints, with all proceeds going directly to Doctors of the World.

Published by the BMJ Publishing Group Limited. For permission to use (where not already granted under a licence) please go to http://group.bmj.com/group/rights-licensing/ permissions 